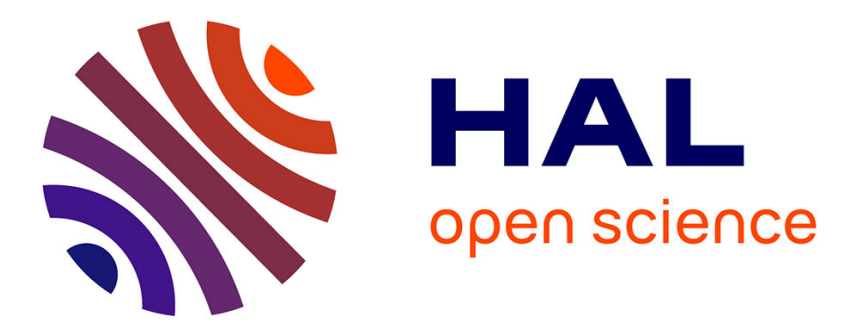

\title{
Preparation of hexaferrite multilayers by tape casting
}

D. Rousselle, D. Autissier

\section{To cite this version:}

D. Rousselle, D. Autissier. Preparation of hexaferrite multilayers by tape casting. Journal de Physique

IV Proceedings, 1993, 03 (C7), pp.C7-783-C7-788. 10.1051/jp4:19937123 . jpa-00251742

\section{HAL Id: jpa-00251742 \\ https://hal.science/jpa-00251742}

Submitted on 1 Jan 1993

HAL is a multi-disciplinary open access archive for the deposit and dissemination of scientific research documents, whether they are published or not. The documents may come from teaching and research institutions in France or abroad, or from public or private research centers.
L'archive ouverte pluridisciplinaire HAL, est destinée au dépôt et à la diffusion de documents scientifiques de niveau recherche, publiés ou non, émanant des établissements d'enseignement et de recherche français ou étrangers, des laboratoires publics ou privés. 


\title{
Preparation of hexaferrite multilayers by tape casting
}

\author{
D. ROUSSELLE and D. AUTISSIER
}

CEA/DAM, Centre d'Etudes de Bruyères-le-Châtel, BP. 12, 91680 Bruyères-le-Châtel, France

\begin{abstract}
Tape casting technics were used to realize a screen with continuous change in characteristics. Different hexaferrite compositions owned by the $\mathrm{Ba}_{3} \mathrm{Co}_{2-\mathrm{x}} \mathrm{Zn}_{\mathrm{x}} \mathrm{Fe}_{24} \mathrm{O}_{41}(\mathrm{Z})$ family were synthetized by coprecipitation method and calcined at $1200^{\circ} \mathrm{C}$ in air. Then a slurry containing this powder is slip casted using tape casting. The tapes are dried under magnetic fied in order to orient the magnetic platelet-shaped particles. Multi-sheets realized with different tapes by hot pressing $\left(65^{\circ} \mathrm{C}, 4 \mathrm{MPa}\right)$ are sintered at $1270^{\circ} \mathrm{C}$ in air. The coefficient of reflexion measured on single composition multi-sheets $\left(\mathrm{Co}_{2} \mathrm{Z}, \mathrm{Co}_{1.5} \mathrm{Zn}_{0 .} \mathrm{Z}\right.$ or $\operatorname{CoZn} Z)$ is compared to the computed value of a multi-composition multi-sheet which is $\mathrm{Co}_{2} \mathrm{Z} / \mathrm{Co}_{1.5} \mathrm{Zn}_{0.5} \mathrm{Z} / \mathrm{CoZnZ}$.
\end{abstract}

\section{1-Introduction.}

All the hexaferrites of $\mathrm{Z}$ family $\left(\mathrm{Ba}_{3} \mathrm{Co}_{2-\mathrm{x}} \mathrm{Zn}_{\mathrm{X}} \mathrm{Fe}_{24} \mathrm{O}_{41}\right)$ present a hexagonal cristalline structure. The $x$ value has an important effect on the magnetic anisotropy, on the resonance frequency and on initial permeability. All compositions have an easy plane of magnetization perpendicular to the $c$ axis. So it is very interesting to align this easy plane parallel to the tape to improve permeability of the material. If tapes corresponding to different $\mathrm{x}$ values in hexaferrite formula are superimposed and co-sintered, the coefficient of reflexion is expected to cover a broader frequency range.

\section{2-Experiments.}

\section{a-Synthesis of the hexaferrite powder.}

The studied $Z$ hexaferrites correspond to $x$ between 0 and 1 . The particles are prepared by coprecipitation chemical method. This process leads to particles with contolled size and morphology.

This technics involves the dissolution of metallic salts $\left(\mathrm{FeCl}_{3}, \mathrm{CoCl}_{2}, \mathrm{ZnCl}_{2}, \mathrm{BaCl}_{2}\right)$. A mixture of iron oxides, hydroxides and carbonate precipitates in an alkaline bath consisting of $\mathrm{Na}_{2} \mathrm{CO}_{3}$. The obtained powder is washed in water to eliminate residual chlorides. Then, the particles are calcined at $1200{ }^{\circ} \mathrm{C}$ in air in order to transform into oxide. $\mathrm{Z}$ and $\mathrm{Y}$ hexaferrite phases are observed by $\mathrm{X}$-ray diffraction (figure 1) on powder after calcination. Particles present a platelet shape as observed by SEM (figure 2). 


\section{b-Preparation of the slurrv.}

Hexaferrite particles (71.8 w\%) with dispersent (Emphos PS21A, 0.5w\%) are ball-milled for $24 \mathrm{~h}$ in solvent (MEK/EtOH, 28.2 w\%). A second stirring is achieved during 3 hours after addition of binders and plasticizer (Rhovinal + DBP + PEG, 11.9 w.\%). Then, the balls are removed and the slurry is deairing slowly during at least 1 hour.

\section{c-Slip casting general principles.}

The general principles of the process are schematized on figure 3 .

\section{Tape casting.}

The slurry is casted on a capton support using a classical tape casting apparatus (figure 4). Tape thickness depends on container moving speed and on depth of adjustable slit. The different parameters used in this work are the following (table 1):

table 1: parameters of slip casting experiments.

\begin{tabular}{|c|c|c|}
\hline Tape width & Depth of slit & Moving speed \\
\hline 60 to $315 \mathrm{~mm}$ & 0.1 to $2 \mathrm{~mm}$ & $1.85 \mathrm{~cm} / \mathrm{s}$ \\
\hline
\end{tabular}

This technics allows us to align hexaferrite particles by a mechanical effect. Orientation degree as high as $70 \%$ (X-Ray determination method) is obtained at this stage.

\section{d-Magnetic orientation.}

The tape is dried under a rotating magnetic field, just after casting, in order to improve the orientation of hexaferrite platelets. The magnetic field intensity is about $0.06 \mathrm{~T}$ and the exposure time exceeds 1 hour. After drying, the orientation degree attains $98 \%$.

\section{e-Realization of the multi-sheets.}

Five to ten tapes $\left(300 \mu \mathrm{m}\right.$ thick each) of one or different compositions are hot pressed $\left(65^{\circ} \mathrm{C}, 4 \mathrm{MPa}\right)$ to obtain a multi-sheet of a few millimeters thick.

\section{E-Sintering.}

Multilayers are sintered in air at $1270^{\circ} \mathrm{C}$ in order to transform into $\mathrm{Z}$ hexaferrite phase.

\section{3- Characterization of the multi-sheet.}

The density, measured by hydrostatic method in bromobenzen, is about $88 \%$ of theoritical density.

Interfaces are no longer observed by optical micrography after sintering. In the case of multicomposition materials, microprobe analysis shows a continuous variation of composition (figure 5). 
The coefficient of reflexion is measured in an APC7 coaxial line on a toroidal sample placed in front of a short-circuit. The computed attenuation of a multi-sheet $\mathrm{CoZnZ} / \mathrm{Co}_{1.5} \mathrm{Zn}_{0.5} / \mathrm{Co}_{2} \mathrm{Z}$ is compared with measured values on single composition (figure 6).

The computed curve corresponding to a multi-composition materials with each layers at matching frequency thickness (Co2Z: $1.82 \mathrm{~mm}, \mathrm{Co} 1.5 \mathrm{Zn} 0.5 \mathrm{Z}: 2.12 \mathrm{~mm}, \mathrm{CoZnZ}: 2.73 \mathrm{~mm}$ ) covers the curves of the single-compositions. Nevertheless, the absolute value of attenuation is lower. It will be very interesting to perform calculation from other values of thickness (different from matching frequency thickness) of singlecomposition samples in order to optimize the multi-composition material.

\section{4-Conclusion.}

In this paper we have shown that we can obtain well-oriented hexaferrite multi-composition multisheets with tape casting method followed by drying under magnetic field. A gradient of composition was observed in the material thickness.

Tape casting technics could be successfully applied to elaboration of many other kinds of functionnally gradient materials. 


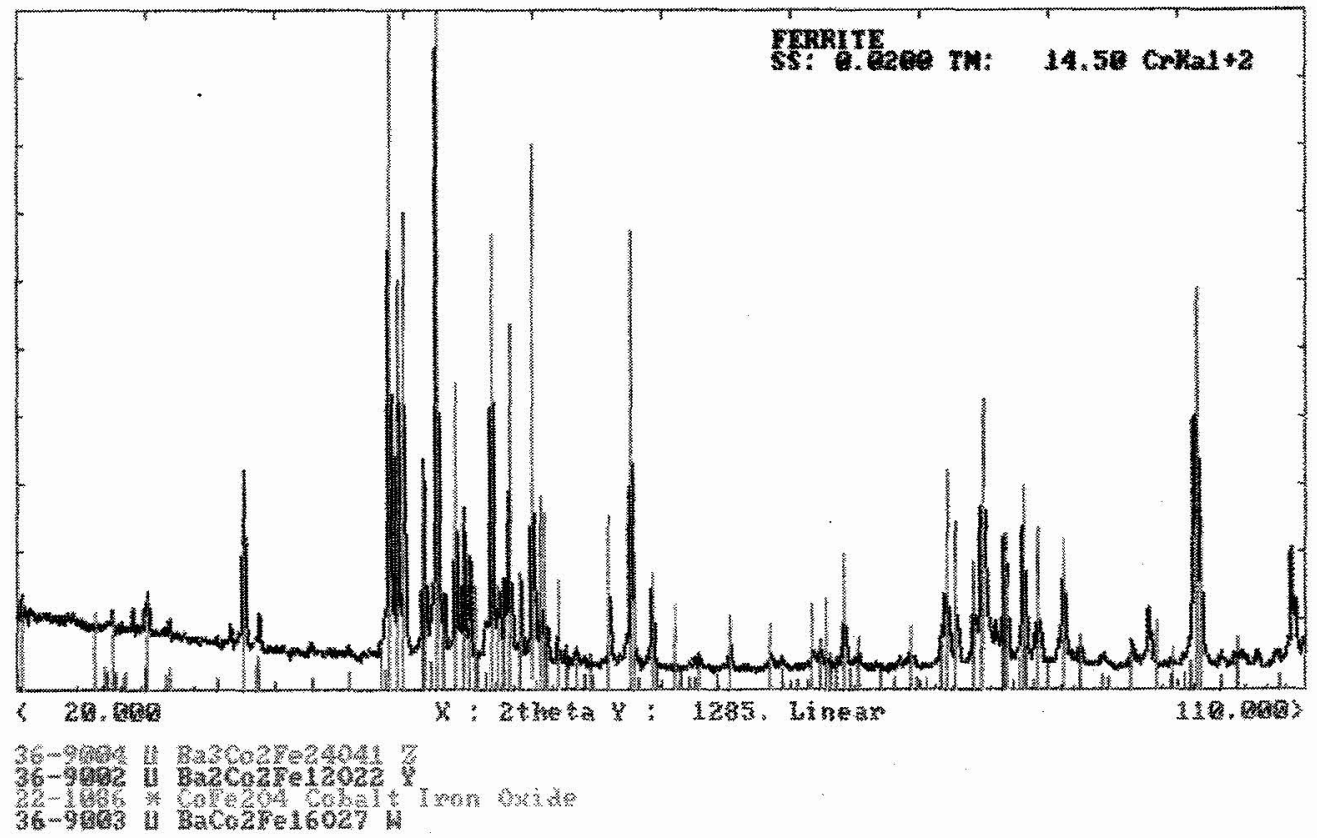

Figure 1: X-Ray diffraction pattern on hexaferrite powder after calcination.

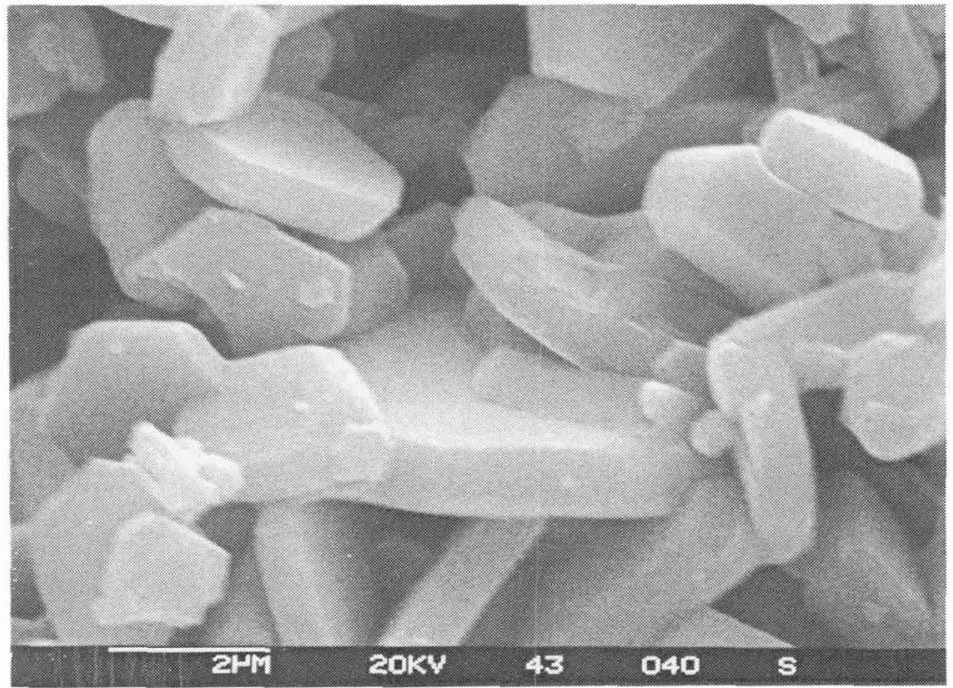

Figure 2: SEM micrograph of hexaferrite particles. 


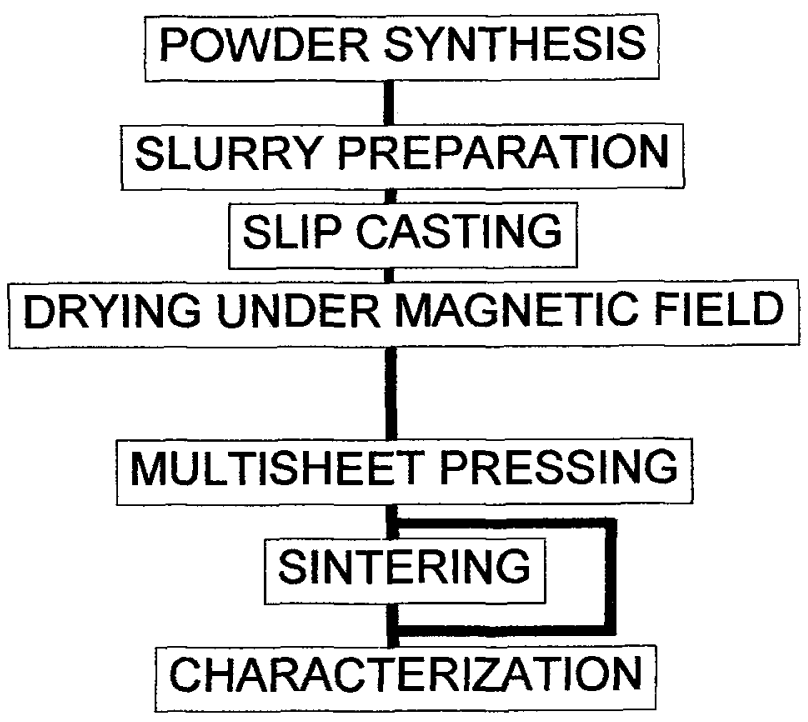

Figure 3: Slip casting general principles.

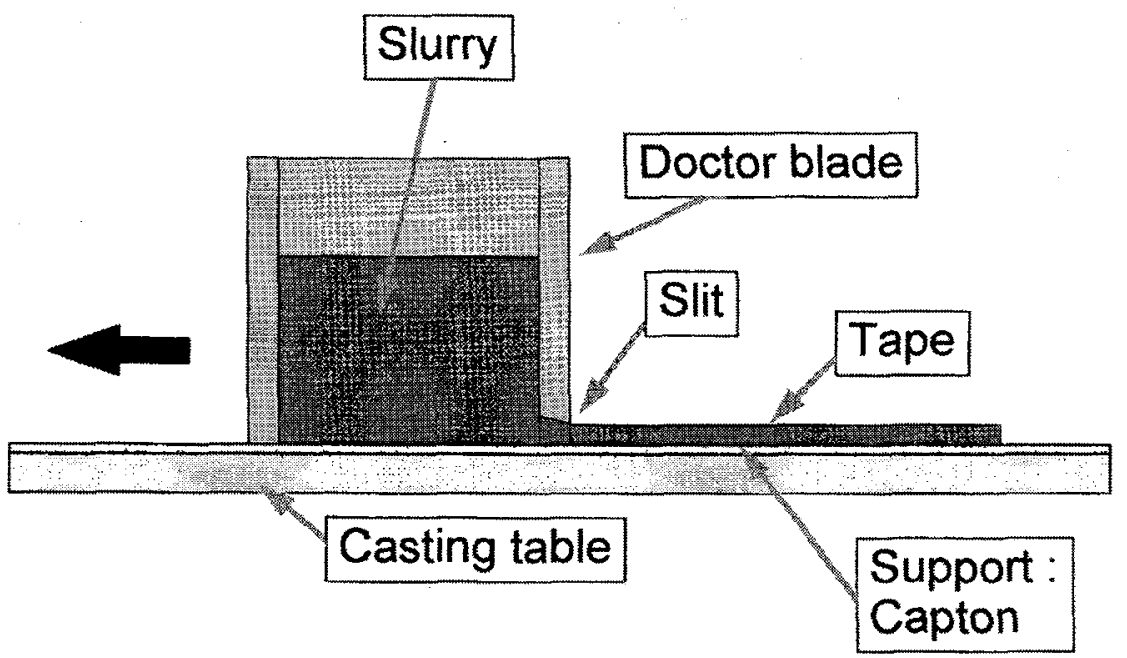

Figure 4: Tape casting apparatus 


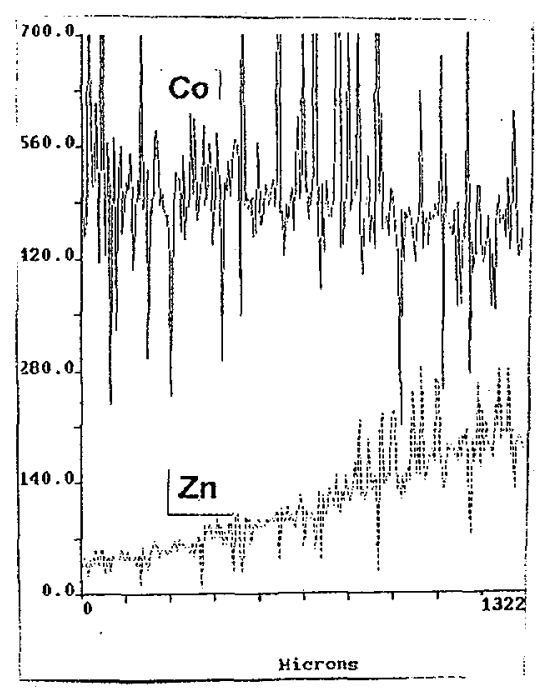

Figure 5: Qualitative microprobe analysis of the composition in the thickness of the material.

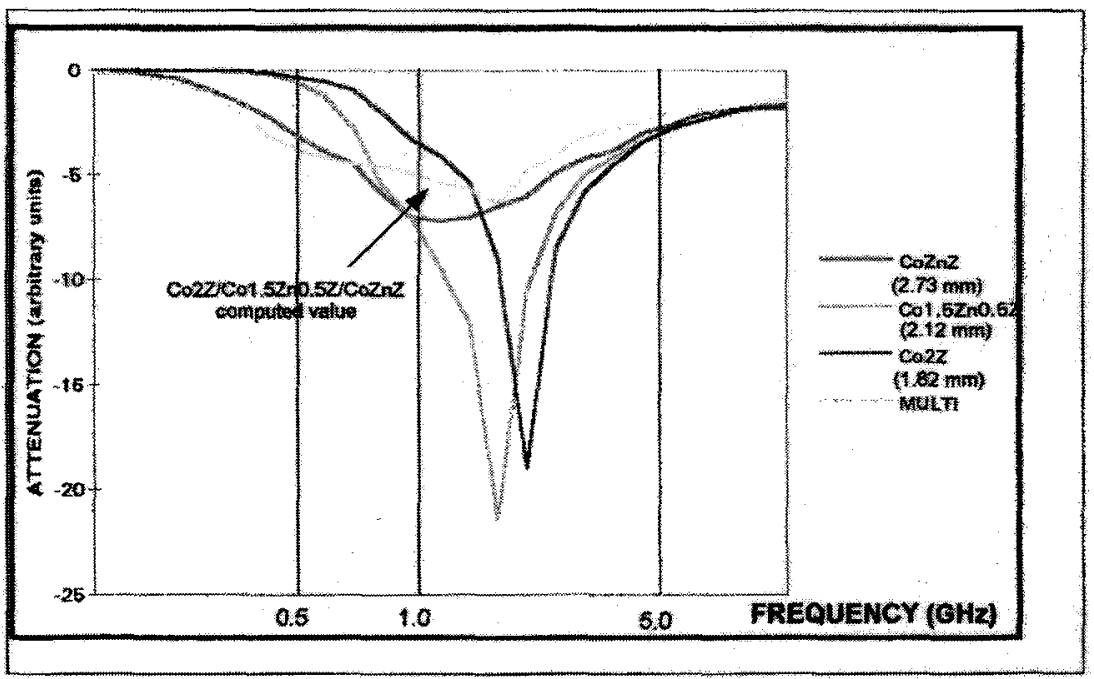

Figure 6: Comparison of computed attenuation of a multi-sheet $\mathrm{CoZnZ} / \mathrm{Co}_{1} . \mathrm{Zn}^{\mathrm{Z}} \mathrm{.}^{\mathrm{Z} / \mathrm{Co}_{2} \mathrm{Z} \text { with measured }}$ values on single-compositions. 